\title{
Aristolochic acid induces apoptosis of human umbilical vein endothelial cells in vitro by suppressing PI3K/Akt signaling pathway
}

\author{
Hong $\mathrm{SHI}^{1,2}$, Jiang-min $\mathrm{FENG}^{1, *}$ \\ ${ }^{1}$ Department of Nephrology, First Affiliated Hospital of China Medical University, Shenyang 110001, China; ${ }^{2}$ Department of Nephrology, \\ Second Hospital of Fushun, Fushun 113001, China
}

\begin{abstract}
Aim: To investigate whether aristolochic acid (AA) induced the apoptosis of human umbilical vein endothelial cells (HUVECs) in vitro and the underlying mechanism.

Methods: HUVECs were treated with AA (5, 10 or $20 \mu \mathrm{g} / \mathrm{mL})$ for 12, 24 and $48 \mathrm{~h}$. Cell viabilities were determined with MTT assay. Hoechst 33258 staining and flow cytometry were used to examine the apoptosis of HUVECs. Western blotting was used to evaluate Akt phosphorylation. Bcl-2 and Bax levels were measured using Western blotting and RT-PCR assays.

Results: Treatment of HUVECs with AA significantly decreased the cell viabilities in dose- and time-dependent manners. Morphological changes of apoptosis were observed in AA-treated cells. AA inhibited Akt activation, which was attenuated by pretreatment of the cells with LY294002 (20 $\mathrm{mmol} / \mathrm{L})$ or wortmannin $(50 \mathrm{nmol} / \mathrm{L})$. Furthermore, AA reduced Bcl-2 levels and increased Bax levels.

Conclusion: AA induces apoptosis of HUVECs in vitro via the PI3K/Akt signaling pathway and by modulating the ratio Bcl-2 and Bax.
\end{abstract}

Keywords: aristolochic acid; HUVECs; apoptosis; PI3K/Akt signaling pathway

Acta Pharmacologica Sinica (2011) 32: 1025-1030; doi: 10.1038/aps.2011.74; published online 18 Jul 2011

\section{Introduction}

Aristolochic acid (AA), an active component of the Chinese herbal medicines derived from the Aristolochia species, has been implicated in AA nephropathy (AAN), which is a progressive tubulointerstitial nephropathy. Studies indicated that blood vessel impairment was present in $\mathrm{AAN}^{[1,2]}$, and could be one of the causes for the progressive tubulointerstitial damage. In renal biopsy samples of AAN patients, the abnormal ultrastructure of endothelial cells within the microvasculature and marked injury of peritubular capillaries were accompanied by low vascular endothelial growth factor (VEGF) levels ${ }^{[3]}$ in tubular cells. It was further indicated that endothelial injury was related to the deterioration of renal function in $\mathrm{AAN}^{[4]}$.

It is well known that VEGF is an important endogenous proangiogenic molecule, which can induce angiogenesis by acting directly on the endothelium in vivo ${ }^{[5]}$. VEGF potently blocks the execution of apoptosis of endothelial cells ${ }^{[6-8]}$. Withdrawal of VEGF by targeted inactivation of the VEGF gene results in massive endothelial cell apoptosis ${ }^{[9,10]}$. Apoptotic

\footnotetext{
* To whom correspondence should be addressed.

E-mail fengjiangmin2007@hotmail.com

Received 2010-11-01 Accepted 2011-04-26
}

endothelial cell death may critically disturb the integrity of the endothelial monolayer and thereby contribute to vascular injury.

VEGF could activate the survival-promoting PI3K/Akt pathway $^{[6,11,12]}$. Activation of the serine/threonine kinase Akt in turn stimulates the phosphorylation of pro-apoptotic proteins such as Bad and consequently inhibits apoptosis execution $^{[13]}$. Moreover, Akt activates the endothelial nitric oxide (NO) synthase, leading to enhanced synthesis of $\mathrm{NO}^{[14,15]}$, which promotes endothelial cell survival by inhibiting the cysteine protease activity of caspases via $S$-nitrosylation of the reactive cysteine residue ${ }^{[16]}$. In addition, recent studies have demonstrated that a PI3K/Akt-dependent enhancement in the expression of the anti-apoptotic protein survivin is important for the apoptosis protective effects of angiogenic factors ${ }^{[17-19]}$. Finally, VEGF mediates the upregulation of the anti-apoptotic protein Bcl- $2^{[20]}$. Thus, the impairment of the intracellular survival signals activated by VEGF has deleterious effects on vessel development.

These data suggests possible inhibitory effect of AA on vessel development indirectly. The objective of the current study was to investigate the direct effects of AA on vascular endothelial cells in vitro and to explore the underlying 
mechanisms.

\section{Materials and methods}

\section{Cell culture and drug treatment}

Human umbilical vein endothelial cells (HUVECs) (American Type Culture Collection, Rockville, MD, USA) were cultured in Dulbecco's modified Eagle's medium (DMEM) (Gibco, USA) supplemented with $10 \%$ fetal bovine serum (Haoyang Biotech Co, China), $100 \mathrm{U} / \mathrm{mL}$ penicillin and $100 \mu \mathrm{g} / \mathrm{mL}$ streptomycin at $37^{\circ} \mathrm{C}$ in a humidified incubator containing $5 \% \mathrm{CO}_{2}$ and $95 \%$ air. For drug treatment, HUVECs were incubated with 5, 10 or $20 \mu \mathrm{g} / \mathrm{mL}$ AA (Sigma, USA) for 12, 24, or $48 \mathrm{~h}$. HUVECs were also pretreated with specific PI3K inhibitor, LY294002 at $20 \mathrm{\mu mol} / \mathrm{L}$ or wortmannin at $50 \mathrm{nmol} / \mathrm{L}$ (Beyotime Institute of Biotechnology, China) for $30 \mathrm{~min}$ prior to treatment with 10 $\mu \mathrm{g} / \mathrm{mL}$ AA.

\section{Cell viability assays}

Cell viability was assessed by the tetrazolium-based semiautomated colorimetric 3-(4,5-dimethylthiazol-2-yl)-2,5diphenyltetrazolium bromide (MTT) reduction assay (Sigma, USA). Cells were seeded at a density of $1 \times 10^{4}$ cells/well in 96-well plates. After $24 \mathrm{~h}$ incubation, cells were treated with AA at 5,10 , or $20 \mu \mathrm{g} / \mathrm{mL}$ for 12,24 , or $48 \mathrm{~h}$. MTT assays were performed as instructed by the manufacturer and absorbance was read at $490 \mathrm{~nm}$ using a microplate reader (Sunrise RC, Tecan, Switzerland). Relative cell viability was expressed as the percentage of the control.

\section{Hoechst 33258 staining assays}

Morphological evaluation of apoptosis was performed using Hoechst 33258 (Beyotime Institute of Biotechnology) according to the manufacturer's instructions. Cells were fixed with $4 \%$ paraformaldehyde for $10 \mathrm{~min}$ at $4^{\circ} \mathrm{C}$ and stained with Hoechst 33258 for 10 min at room temperature in the dark. Nuclear morphology was then examined under a fluorescent microscope (Leica, Wetzlar, Germany).

\section{Flow cytometric studies}

Flow cytometry using annexin V-FITC and propidium iodide (PI) double staining was performed using the annexin V-FITC apoptosis detection kit (Jinmei Biotech Co, China). Cells were harvested, washed twice with cold PBS and resuspended at $1 \times 10^{6}$ cells $/ \mathrm{mL}$ in $100 \mu \mathrm{L}$ binding buffer $(10 \mathrm{mmol} / \mathrm{L}$ Hepes/ $\mathrm{NaOH}, \mathrm{pH} 7.4,140 \mathrm{mmol} / \mathrm{L} \mathrm{NaCl}$ and $2.5 \mathrm{mmol} / \mathrm{L} \mathrm{CaCl}_{2}$ ). Annexin V-FITC $(5 \mu \mathrm{L})$ and $10 \mu \mathrm{L}$ PI $(20 \mu \mathrm{g} / \mathrm{mL})$ were added to the cell suspension $(100 \mu \mathrm{L})$ in the dark followed by incubation at room temperature for 15 min in the dark and then mixed with $400 \mu \mathrm{L}$ binding buffer, and flow cytometry (FACScalibur, Becton-Dickison, USA) was carried out within $1 \mathrm{~h}$. Data analysis was performed using the Modifit Flow Cytometry Software.

\section{Western blotting studies}

HUVECs were lysed using RIPA lysis buffer containing 50 $\mathrm{mmol} / \mathrm{L}$ Tris- $\mathrm{HCl}$ ( $\mathrm{pH} 7.4$ ), $150 \mathrm{mmol} / \mathrm{L} \mathrm{NaCl}, 1 \%$ sodium deoxycholate, 1\% NP-40, 1 mmol/L phenylmethylsulfonyl fluoride and $1 \mathrm{mmol} / \mathrm{L}$ EDTA. Protein concentration was determined by Bradford assay (Bio-Rad, USA). Samples containing $10 \mu \mathrm{g}$ total protein were resolved by $12 \%$ sodium dodecyl sulfate polyacrylamide gel electrophoresis (SDS-PAGE) and then electrophoretically transferred to a polyvinylidene difluoride membrane. The membranes were incubated with $5 \%$ non-fat dried milk in TBS-Tween $20(10 \mathrm{mmol} / \mathrm{L}$ Tris-buffered saline with $0.1 \%$ Tween 20 ) at room temperature for $1 \mathrm{~h}$, and then incubated with anti-phospho-S473 Akt polyclonal antibody, anti-Bcl-2 polyclonal antibody, or anti-Bax polyclonal antibody (ABZOOM, USA) overnight at $4{ }^{\circ} \mathrm{C}$. After incubation with goat anti-rabbit horseradish peroxidase-conjugated secondary antibody (Santa Cruz Biotechnology, USA) for $2 \mathrm{~h}$ at room temperature, the immune complexes were visualized by enhanced chemiluminescence methods. Band intensity was analyzed by the Scion Image software and compared with the internal standard $\beta$-actin.

\section{Caspase- 3 activity assay}

Caspase-3 activity was assessed via a colorimetric assay according to the manufacturer's protocols (BD Biosciences, USA). After treatment, the cells were collected by trypsinization and washed twice with ice-cold PBS followed by centrifugation. The cellular pellet was resuspended in cell lysis buffer and incubated on ice for $10 \mathrm{~min}$. Lysates were centrifuged for $1 \mathrm{~min}$ at 10000 revolutions per minute, and the supernatants were assayed for caspase-3 activity in reaction buffer/DTT Mix. After addition of caspase-3 substrate (Ac-DEVD-pNA), samples were incubated for $4 \mathrm{~h}$ at $37^{\circ} \mathrm{C}$ and caspase-3 activity (pNA) was measured by a spectrofluorometer (Bio-Rad, USA) at $405 \mathrm{~nm}$. Caspase-3 activity was expressed as the fold of the control.

\section{RT-PCR analysis}

The cells were harvested after AA treatment and washed twice in cold PBS. Total RNA was extracted using the TRIzol reagent (Invitrogen, USA) according to the manufacturer's instructions and RNA was dissolved in RNase-free water. The concentration and purity of RNA were determined using a UV300 spectrophotometer at $260 \mathrm{~nm}$ and $280 \mathrm{~nm}$. Complementary DNA (cDNA) was synthesized in a volume of 20 $\mu \mathrm{L}$ with a cDNA synthesis kit (Takara Biotechnology, China) according to the manufacturer's protocol. The obtained cDNA was amplified by PCR. The sequences of primers used were: 5'-TAATTGCCAAGCACCGCTTC-3' (sense) and 5'-CCAGGTATGCATCATGTGAG-3' (antisense) for Bcl-2; 5'-AGTAACATGGAGCTGCAGAG-3' (sense) and 5'-ACAAAGATGGTCACGGTCTG-3' (antisense) for Bax; 5' -TCTACAATGAGCTGCGTGTG-3' (sense) and 5'-GGATGTCCACGTCACACTTC-3' (antisense) for $\beta$-actin. The PCR conditions were: $95^{\circ} \mathrm{C}$ for $2 \mathrm{~min}$; 30 cycles of $95^{\circ} \mathrm{C}$ for $45 \mathrm{~s}, 55^{\circ} \mathrm{C}$ for $45 \mathrm{~s}$, and $72{ }^{\circ} \mathrm{C}$ for $1 \mathrm{~min}$, followed by a final extension at $72{ }^{\circ} \mathrm{C}$ for 7 min. The amplified PCR products were separated by $1.5 \%$ agarose (Amersco, USA) gel electrophoresis and visualized by ethidium bromide staining. Bcl-2 and Bax levels were normal- 
ized against $\beta$-actin.

\section{Statistical analysis}

The data were expressed as mean \pm SD. All data were analyzed using the SPSS13.0 program (SPSS Inc, Chicago, IL, USA), and statistical differences were determined by paired sample $t$-test or one way ANOVA-test (SNK post test). $P<0.05$ was considered statistically significant.

\section{Results}

\section{AA reduces viabilities}

Prior to the investigation of the toxic effect of AA on HUVECs, we sought to understand the effect of AA on cell viability by MTT assay. The cells were exposed to 5, 10, or $20 \mu \mathrm{g} / \mathrm{mL}$ AA for 12, 24, and $48 \mathrm{~h}$, respectively. As shown in Figure 1, AA significantly inhibited cell viability compared to controls in a dose- and time-dependent manner.

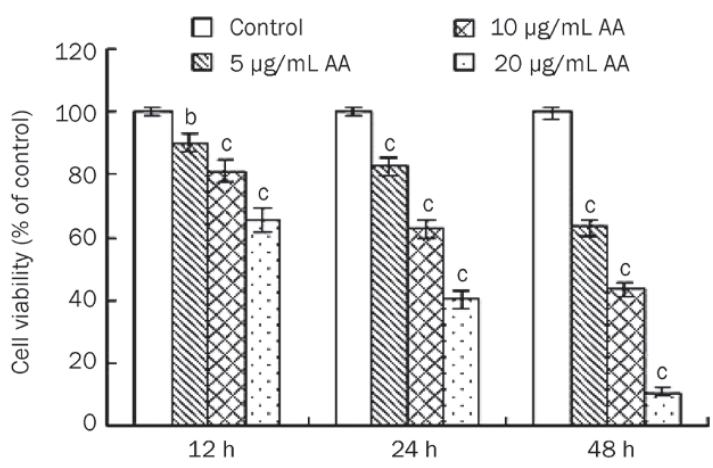

Figure 1. Effect of AA on the viability of HUVECs measured by the MTT assay. Mean \pm SD. $n=5 .{ }^{b} P<0.05,{ }^{c} P<0.01$ for the AA group vs the control group.

\section{AA induces apoptosis of HUVECs}

To further examine morphological changes in response to AA, both control and AA-treated cells were stained with fluorescent dye Hoechst 33528 and visualized under a fluorescent microscope. Figure 2A shows the results of Hoechst 33528 staining for AA treated-cells at the concentrations of 5, 10, or $20 \mu \mathrm{g} / \mathrm{mL}$ for $24 \mathrm{~h}$. The untreated cells stained uniformly blue. At $5 \mu \mathrm{g} / \mathrm{mL} \mathrm{AA}$, cells began to display apoptotic morphology. Fluorescence was detected in the nuclear region of HUVECs, indicating the presence of DNA fragmentation. At 10 and $20 \mu \mathrm{g} / \mathrm{mL}$ of $\mathrm{AA}$, nuclear condensation and fragmentation became more apparent. The chromatin was condensed into lumps, exhibiting punctuated morphology typical of apoptotic cells. These observations provided evidence that AA induced apoptosis in HUVECs.

To gain further insight into the pro-apoptotic effect of AA on HUVECs quantitatively, we examined the percentage of apoptotic cells exposed to AA by flow cytometry using annexin V-FITC and PI staining. The percentage of apoptotic cells was $6.64 \% \pm 0.78 \%$ in the control. After treatment with 5, 10 , or $20 \mu \mathrm{g} / \mathrm{mL}$ AA for $24 \mathrm{~h}$, the percentage of apoptotic cells
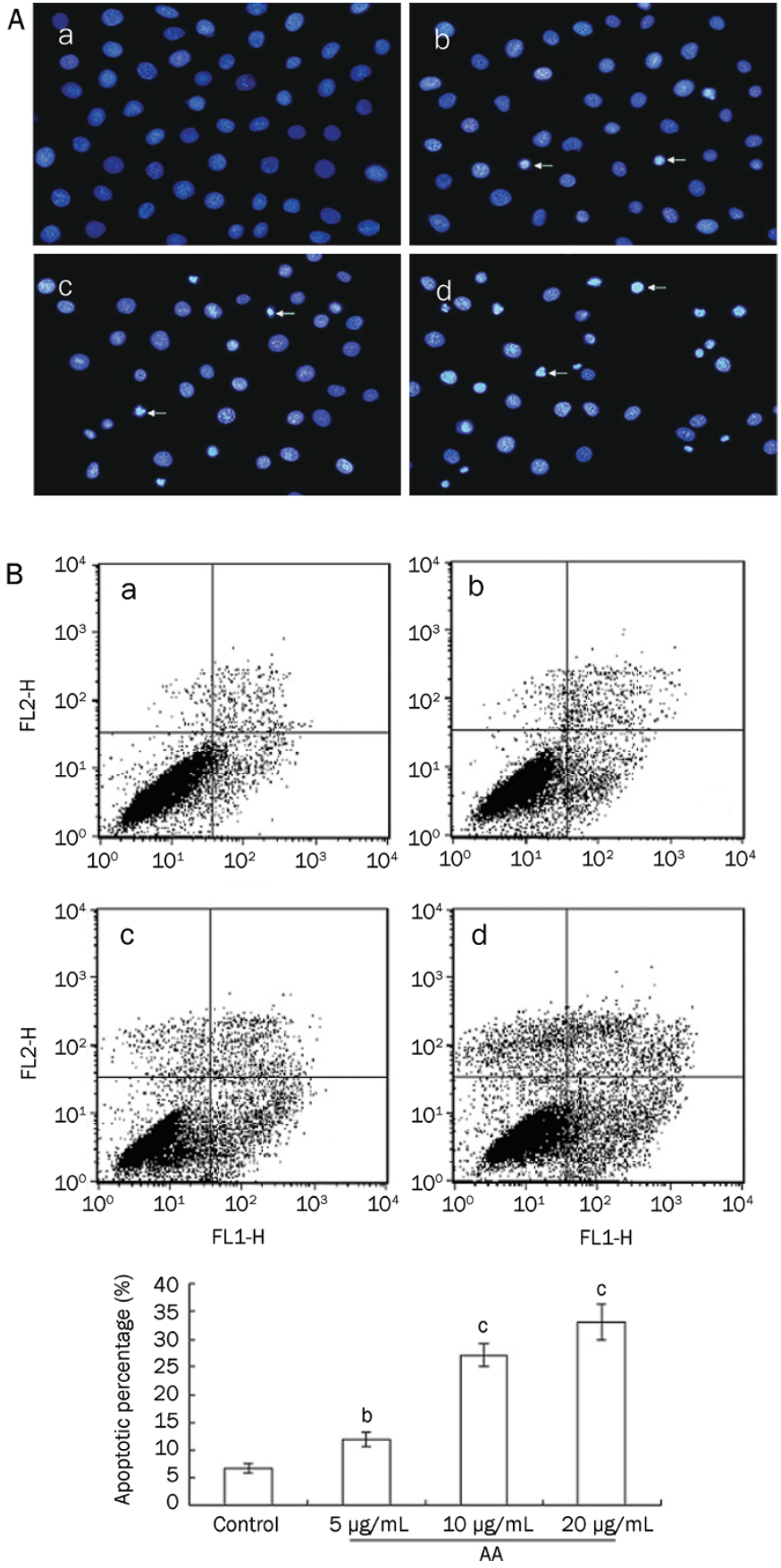

Figure 2. (A) The morphological changes of HUVECs detected by Hoechst 33258 staining. (a) Control; (b) $5 \mu \mathrm{g} / \mathrm{mL}$ AA; (c) $10 \mu \mathrm{g} / \mathrm{mL} \mathrm{AA;} \mathrm{(d)} 20$ $\mu \mathrm{g} / \mathrm{mL}$ AA. (B) The apoptotic percentage of HUVECs measured by flow cytometry. (a) Control; (b) $5 \mu \mathrm{g} / \mathrm{mL} \mathrm{AA;} \mathrm{(c)} 10 \mu \mathrm{g} / \mathrm{mL} \mathrm{AA;} \mathrm{(d)} 20 \mu \mathrm{g} / \mathrm{mL}$ AA. Mean \pm SD. $n=5 .{ }^{b} P<0.05,{ }^{c} P<0.01$ for the AA group vs the control group. $\mathrm{X}$-axis represents annexin $\mathrm{V}$-FITC staining and $\mathrm{y}$-axis represents $\mathrm{PI}$ staining. Left lower quadrant means annexin V-FITC and PI negative. Right lower quadrant means annexin-V FITC positive and PI negative. Right superior quadrant means annexin V-FITC and PI positive. Left superior quadrant means PI positive. Viable cells were annexin V-FITC and PI negative, cells in early-stage apoptosis were annexin-V FITC positive and PI negative, cells in late-stage apoptosis were annexin V-FITC and PI positive, dead cells were PI positive. The cells in early and late-stage apoptosis were defined as apoptotic. 
increased to $11.79 \% \pm 1.29 \%, 27.79 \% \pm 2.56 \%$, and $32.33 \% \pm 3.82 \%$, respectively. Significant difference was observed between AA treated cells and controls $(P<0.05$ or $P<0.01)$ (Figure $2 \mathrm{~B})$.

\section{AA suppresses the activation of Akt}

To explore the possible mechanism for the pro-apoptotic effect of AA, we investigated the effect of AA on Akt activation. Western blotting studies using anti-phospho-S473 Akt antibodies analysis showed that AA $(10 \mu \mathrm{g} / \mathrm{mL})$ inhibited the activation of Akt in HUVECs after 15, 30, 60, or 120 min of drug exposure, with the minimum activation at approximately 30 min (Figure 3A). In addition, as indicated in Figure 3B, AA also inhibited Akt activation at $30 \mathrm{~min}$ in a dose-dependent manner at doses ranging from 5 to $20 \mu \mathrm{g} / \mathrm{mL}$. We further tested the effect of PI3K specific inhibitors LY294002 or wortmannin on AA-induced Akt inactivation in HUVECs. The results showed that pretreatment with LY294002 or wortmannin for 30 min prior to stimulation with AA $(10 \mu \mathrm{g} / \mathrm{mL})$ for 30 min attenuated the inhibitory effect of AA on Akt activation, suggesting that the effect of AA on Akt inactivation was mediated through the PI3K/Akt signaling pathway (Figure 3C).

\section{AA activates caspase- 3 via the PI3K/Akt pathway}

We further measured caspase-3 activity of HUVECs exposed to AA. As shown in Figure 4, a marked increase in caspase-3 activity was observed in cells incubated with $10 \mu \mathrm{g} / \mathrm{mL}$ AA for $24 \mathrm{~h}(1.645 \pm 0.076$ vs $1.000 \pm 0.037$ for the control, $P<0.01)$, and the increase was attenuated when LY294002 $(1.263 \pm 0.045$ vs $10 \mu \mathrm{g} / \mathrm{mL}$ AA, $P<0.01)$ or wortmannin $(1.205 \pm 0.047$ vs 10 $\mu \mathrm{g} / \mathrm{mL}$ AA, $P<0.01)$ was added before AA treatment, suggesting that AA induced apoptosis of HUVECs through the PI3K/ Akt signaling pathway.

\section{AA down-regulates the expression of Bcl-2}

To further explore the possible mechanism of the pro-apoptotic effect of AA, we investigated the effect of AA on the expression of anti-apoptotic gene Bcl-2 in HUVECs. Exposure to 5,10 or $20 \mu \mathrm{g} / \mathrm{mL}$ AA for $24 \mathrm{~h}$ decreased the level of Bcl-2 protein expression in HUVECs to $0.57 \pm 0.032,0.44 \pm 0.028$ or $0.35 \pm 0.031$, respectively, which was significantly lower than that of controls $(0.65 \pm 0.026)(P<0.05$ or $P<0.01)$ (Figure 5A).

We further detected the effect of AA on the expression of Bcl-2 mRNA. Treatment with various concentrations of AA $(5,10,20 \mu \mathrm{g} / \mathrm{mL})$ for $24 \mathrm{~h}$ significantly reduced the expressions of Bcl- 2 mRNA $(0.58 \pm 0.037,0.42 \pm 0.03$ and $0.36 \pm 0.024$, respectively) compared with the controls $(0.66 \pm 0.022)(P<0.05$ or $P<0.01$ ) (Figure $5 \mathrm{~B}$ ).

\section{AA up-regulates the expression of Bax}

The Bax/Bcl-2 family are important apoptotic regulating factors in the intrinsic apoptotic pathway and the ratio of Bax/ Bcl-2 is critical to cell survival. We next determined the expression of Bax protein by Western blotting. Following a 24-h treatment with 5, 10, or $20 \mu \mathrm{g} / \mathrm{mL} \mathrm{AA}$, we detected increased levels of the Bax protein $(0.38 \pm 0.022,0.56 \pm 0.032$, and $0.45 \pm 0.028$, respectively) compared with the control
A
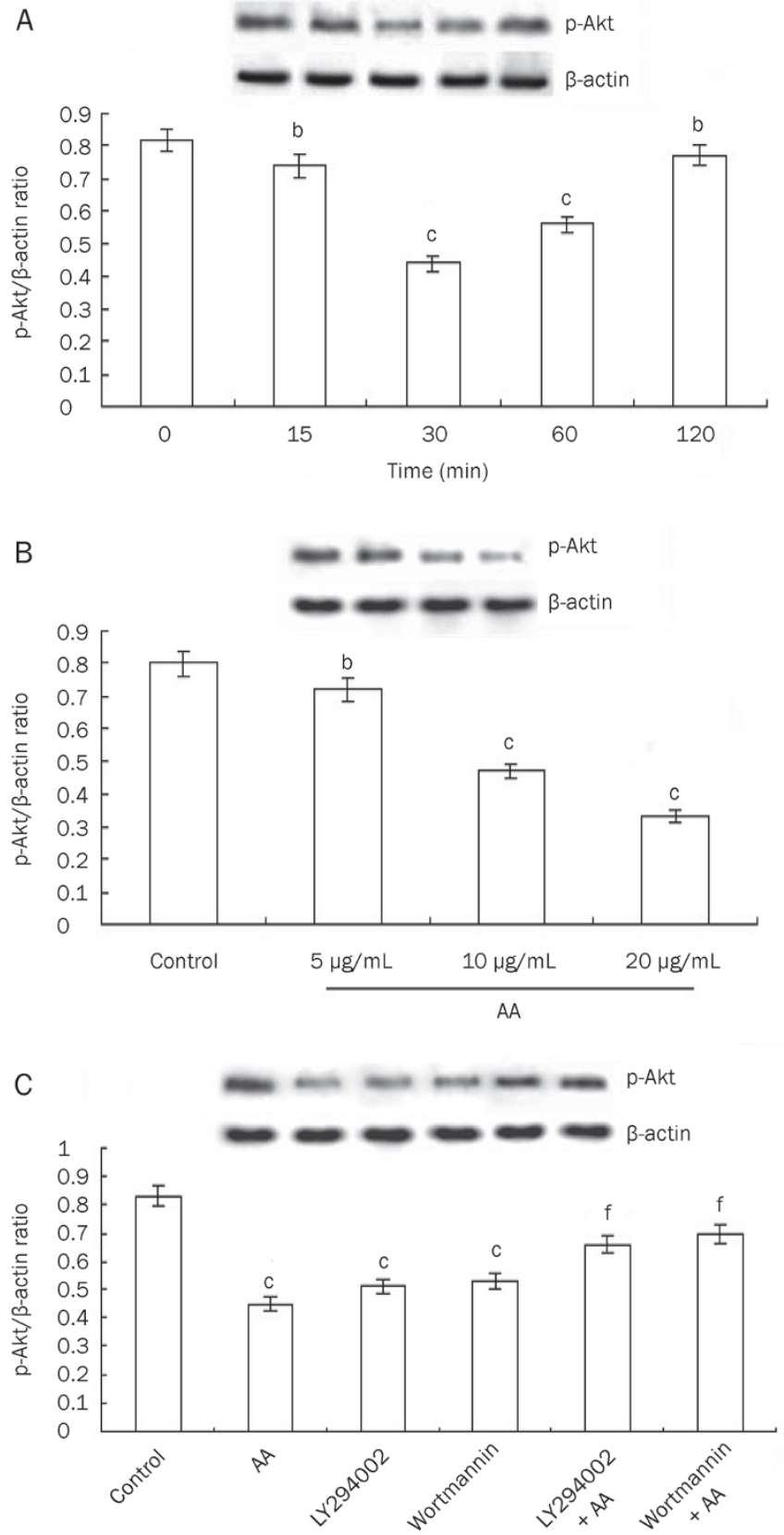

Figure 3. Phosphorylated Akt in HUVECs detected by Western blotting. (A) $10 \mu \mathrm{g} / \mathrm{mL}$ AA for 0, 15, 30, 60, or $120 \mathrm{~min}$; (B) 5, 10 and $20 \mu \mathrm{g} / \mathrm{mL}$ AA for $30 \mathrm{~min}$; (C) effects of LY294002 and wortmannin on phospho-Akt expression induced by AA in HUVECs. Mean \pm SD. $n=5$. ${ }^{b} P<0.05,{ }^{\mathrm{C}} P<0.01$ for the AA group vs the control group; ${ }^{f} P<0.01$ for the LY294002+AA group and wortmannin+AA group vs the AA group.

(0.32 \pm 0.027$)$. There was a significant difference in Bax expression levels between AA-induced cells and the control $(P<0.05$ or $P<0.01$, Figure 6A).

This study also detected the effect of AA on the expression of Bax mRNA. The results showed that the expression of Bax mRNA stimulated by AA $(5,10$, or $20 \mu \mathrm{g} / \mathrm{mL})$ for $24 \mathrm{~h}$ was significantly increased $(0.41 \pm 0.031,0.55 \pm 0.038$ and $0.48 \pm 0.023$, respectively) compared with that of the control $(0.35 \pm 0.024)$ 


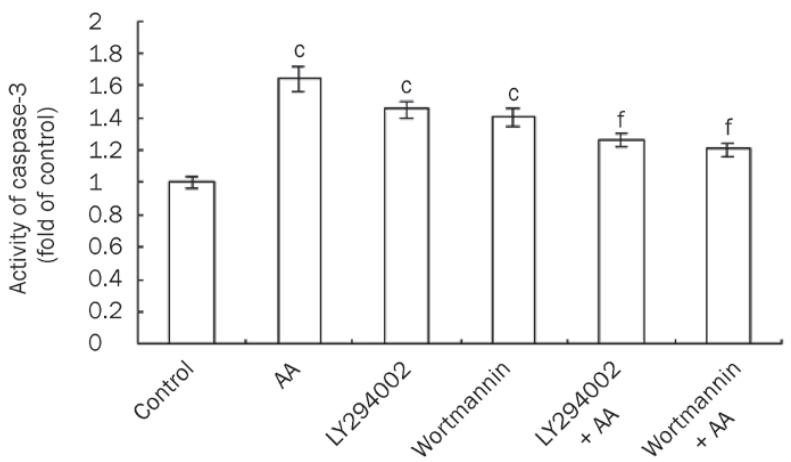

Figure 4. Caspase-3 activity of HUVECs determined by the colorimetric method. Mean \pm SD. $n=5$. ${ }^{\circ} P<0.01$ for the AA group vs control group; ${ }^{f} P<0.01$ for the LY294002+AA group and the wortmannin+AA group vs the AA group.
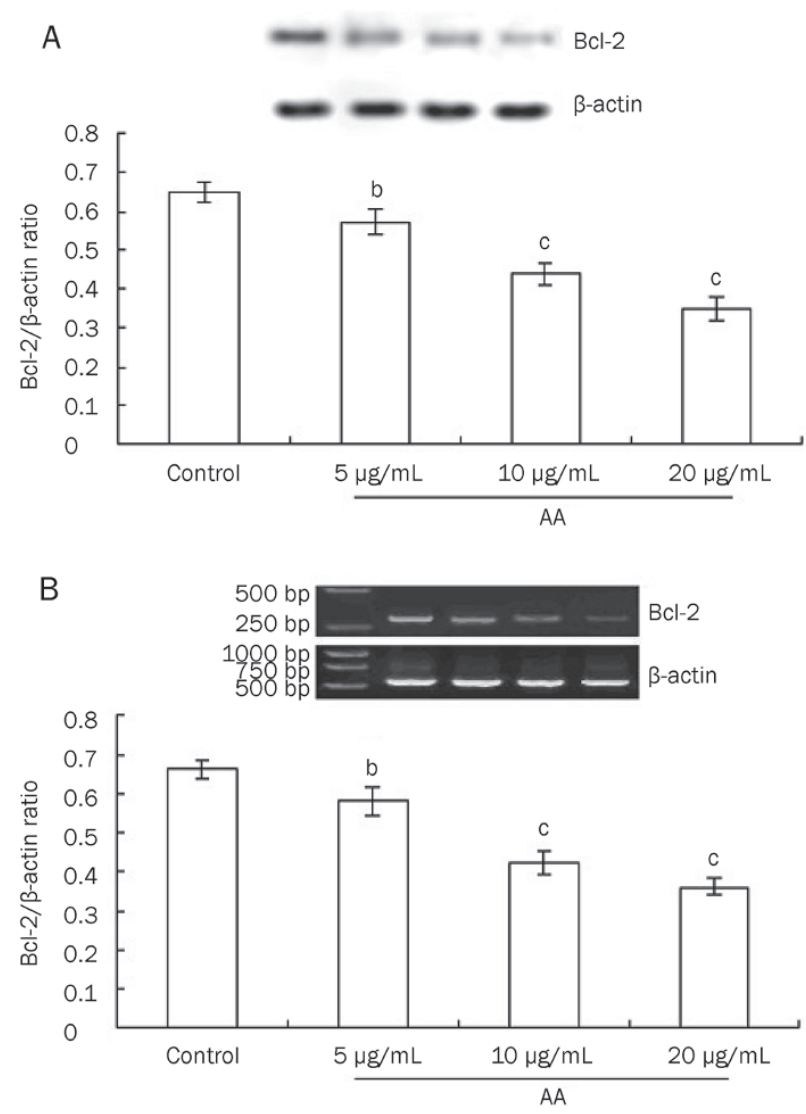

Figure 5. (A) The expression of $\mathrm{Bcl}-2$ protein detected by Western blotting. (B) The expression of Bcl-2 mRNA detected with RT-PCR. Mean \pm SD. $n=5$. ${ }^{\mathrm{b}} P<0.05,{ }^{\mathrm{C}} P<0.01$ for the AA group vs the control group.

$(P<0.05$ or $P<0.01$, Figure 6B).

\section{Discussion}

Many Chinese medicinal herbs contain AA, which has been extensively used to treat digestive and urogenital system diseases. AA reacts with cellular proteins and DNA, resulting in multiple forms of toxicity ${ }^{[21]}$. AAN is a progressive tubuloint-
A
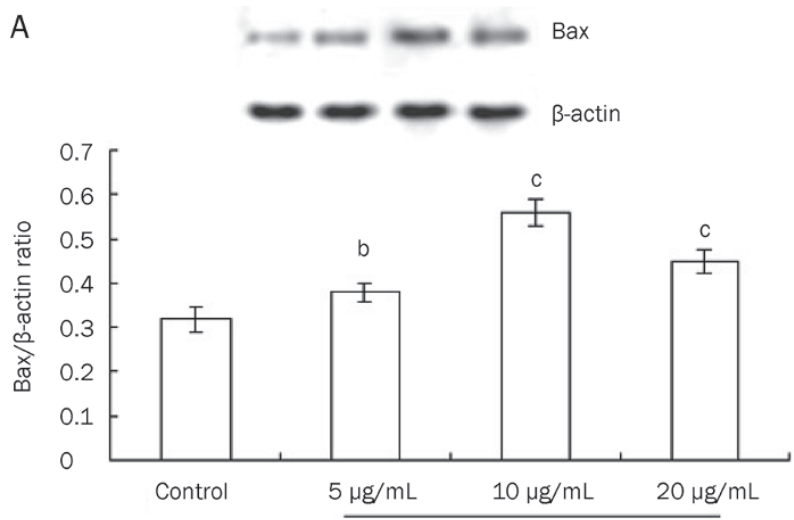

AA

B
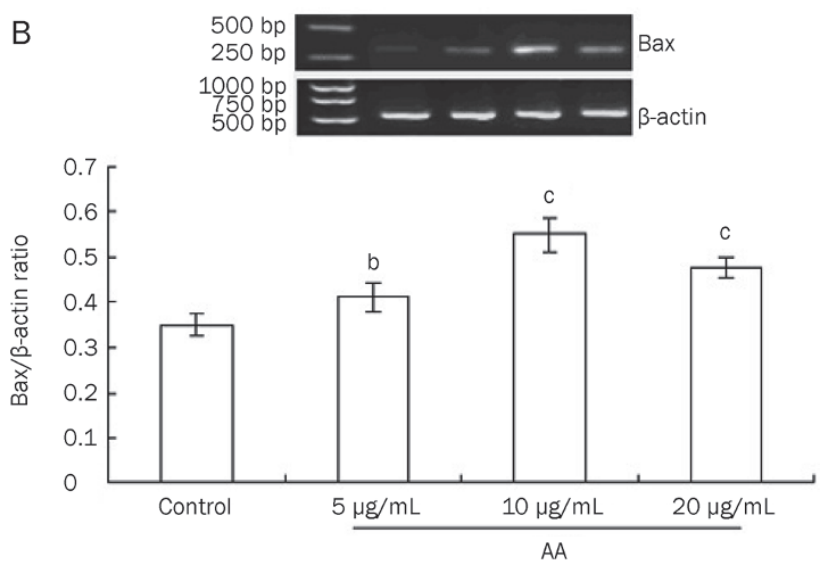

Figure 6. (A) The expressions of Bax protein detected by Western blotting. (B) The expression of Bax mRNA by RT-PCR. Mean \pm SD. $n=5 .{ }^{b} P<0.05$, ${ }^{\mathrm{c}} P<0.01$ for the AA group vs the control group.

erstitial renal disease caused by AA intake. Progressive loss of peritubular capillaries was demonstrated in AAN model, which was associated with decreased expression of VEGF ${ }^{[22]}$. Recently, VEGF has emerged as a crucial element in vascular homeostasis. VEGF is an angiogenic factor and an endothelial cell survival factor ${ }^{[6]}$. Withdrawal of VEGF by targeted inactivation of the VEGF gene results in massive endothelial cell apoptosis $^{[9,10]}$. Vascular endothelial cells form the inner lining of all blood vessels and play an important role in regulating vascular function. Since the vascular endothelium is involved in various physiological processes, endothelial cell apoptosis (and dysfunction) may constitute an initial step in a variety of pathological situations such as atherosclerosis and hypertension. The data document the inhibitory effect of AA on vessel development indirectly. The direct effects of AA on vascular endothelial cells are unclear. Our study showed that AA could induce endothelial cell apoptosis and increase activation of caspase-3. Moreover, we determined the signaling pathway involved in the pro-apoptotic effect of AA: we found that exposure of cells to AA or the PI3K inhibitor (wortmannin or LY294002) alone could likewise cause inactivation of Akt, and pretreatment with PI3K inhibitor (LY294002 or wortmannin) to block primarily the PI3K/Akt pathway before AA treatment could attenuate the effect of AA on the activation of Akt and 
caspase-3 activity, suggesting that AA-induced endothelial cell apoptosis may be, at least partly, through inhibiting the PI3K/ Akt signaling pathway. Akt, also known as protein kinase $\mathrm{B}(\mathrm{PKB})$, was recognized as a major downstream target of $\mathrm{PI} \mathrm{K}^{[23]}$. The full activation of Akt requires phosphorylation at both Thr 308 and Ser 473. VEGF inhibits endothelial cell apoptosis through activating the PI3K/Akt signal pathway ${ }^{[6,11,12]}$. In endothelial cells, Akt activation has been reported to promote cell survival ${ }^{[15]}$. LY294002 and wortmannin are two broad-specific inhibitors of P13K. They can completely inhibit PI3K activity, thereby blocking the activation of Akt. Our study directly observed Akt (Ser 473) phosphorylation after treatment with AA. The results of our study indicated that AA has a pro-apoptotic effect on endothelial cells, and, at least partly, via blocking PI3K/Akt pathway.

Moreover, there was evidence that VEGF prevents the apoptosis of endothelial cells via up-regulating the expression of anti-apoptotic gene $\mathrm{Bcl}-2^{[20]}$. The Bcl-2 family play a crucial role in the control of apoptosis. The Bcl-2 family of proteins contain both inhibitors $\left(\mathrm{Bcl}-2, \mathrm{Bcl}-\mathrm{x}_{\mathrm{L}}\right)$ and inducers $\left(\mathrm{Bcl}-\mathrm{x}_{\mathrm{S}}\right.$, Bax, Bid, Bad, Bak) of apoptosis. The balance between antiapoptotic and pro-apoptotic Bcl-2 family members is critical to determining if a cell undergoes apoptosis. In the present study, we observed that AA could reduce Bcl-2 expression and improve Bax expression. The level of Bax protein expression was significantly decreased in cells incubated with $20 \mu \mathrm{g} / \mathrm{mL}$ AA; the explanation could be the massive necrosis.

Our study demonstrates that AA can cause the apoptosis of endothelial cells. This apoptosis may be related to the inhibition of PI3K/Akt signaling pathway and modulating the ratio of Bcl-2 and Bax.

\section{Acknowledgements}

We wish to thank the Tumor Research Institute of China Medical University for its valuable help.

\section{Author contribution}

Jiang-min FENG and Hong SHI designed the research; and Hong SHI performed the research, analyzed the data and wrote the manuscript.

\section{References}

1 Depierreux M, Van Damme B, Vanden Houte K, Vanherweghem JL. Pathologic aspects of a newly described nephropathy related to the prolonged use of Chinese herbs. Am J Kidney Dis 1994; 24: 172-80.

2 Yang L, Li XM, Wang SX, Wang HY. Peritubular capillary injury in Chinese herb guan-mu-tong-induced acute tubular necrosis. Zhonghua Nei Ke Za Zhi 2005; 44: 525-9.

3 Yang L, Li X, Wang $\mathrm{H}$. Possible mechanisms explaining the tendency towards interstitial fibrosis in aristolochic acid-induced acute tubular necrosis. Nephrol Dial Transplant 2007; 22: 445-56.

4 Sun D, Feng JM, Dai C, Sun L, Jin T, Wang ZQ, et al. Influence of hypoxia caused by impairment of peritubular capillary on the progression of chronic aristolochic acid nephropathy. Zhonghua Yi Xue Za Zhi 2006; 86: 1464-9.

5 Ferrara N, Houck K, Jakeman L, Leung DW. Molecular and biological properties of the vascular endothelial growth factor family of proteins. Endocr Rev 1992; 13: 18-32.

6 Gerber HP, McMurtrey A, Kowalski J, Yan M, Keyt BA, Dixit V, et al. Vascular endothelial growth factor regulates endothelial cell survival through the phosphatidylinositol 3'-kinase/Akt signal transduction pathway. Requirement for Flk-1/KDR activation. J Biol Chem 1998; 273: 30336-43.

7 Fujio Y, Walsh K. Akt mediates cytoprotection of endothelial cells by vascular endothelial growth factor in an anchorage-dependent manner. J Biol Chem 1999; 274: 16349-54.

8 Araki S, Simada Y, Kaji K, Hayashi H. Role of protein kinase C in the inhibition by fibroblast growth factor of apoptosis in serum-depleted endothelial cells. Biochem Biophys Res Commun 1990; 172: 1081-5.

9 Carmeliet P, Ferreira V, Breier G, Pollefeyt S, Kieckens L, Gertsenstein $\mathrm{M}$, et al. Abnormal blood vessel development and lethality in embryos lacking a single VEGF allele. Nature 1996; 380: 435-9.

10 Ferrara N, Carver-Moore K, Chen H, Dowd M, Lu L, O'Shea KS, et al. Heterozygous embryonic lethality induced by targeted inactivation of the VEGF gene. Nature 1996; 380: 439-42.

11 Kim I, Kim HG, So JN, Kim JH, Kwak HJ, Koh GY. Angiopoietin-1 regulates endothelial cell survival through the phosphatidylinositol 3'-Kinase/Akt signal transduction pathway. Circ Res 2000; 86: 24-9.

12 Dimmeler S, Zeiher AM. Akt takes center stage in angiogenesis signaling. Circ Res 2000; 86: 4-5.

13 Khwaja A. Akt is more than just a Bad kinase. Nature 1999; 401: 33-4.

14 Dimmeler S, Fleming I, FissIthaler B, Hermann C, Busse R, Zeiher AM. Activation of nitric oxide synthase in endothelial cells by Aktdependent phosphorylation. Nature 1999; 399: 601-5.

15 Fulton D, Gratton JP, McCabe TJ, Fontana J, Fujio Y, Walsh K, et al. Regulation of endothelium-derived nitric oxide production by the protein kinase Akt. Nature 1999; 399: 597-601.

16 Dimmeler S, Haendeler J, Nehls M, Zeiher AM. Suppression of apoptosis by nitric oxide via inhibition of interleukin-1beta-converting enzyme (ICE)-like and cysteine protease protein (CPP)-32-like proteases. J Exp Med 1997; 185: 601-8.

17 Papapetropoulos A, Fulton D, Mahboubi K, Kalb RG, O'Connor DS, Li $\mathrm{F}$, et al. Angiopoietin-1 inhibits endothelial cell apoptosis via the Akt/ survivin pathway. J Biol Chem 2000; 275: 9102-5.

18 O'Connor DS, Schechner JS, Adida C, Mesri M, Rothermel AL, Li F, et al. Control of apoptosis during angiogenesis by survivin expression in endothelial cells. Am J Pathol 2000; 156: 393-8.

19 Tran J, Rak J, Sheehan C, Saibil SD, LaCasse E, Korneluk RG, et al. Marked induction of the IAP family antiapoptotic proteins survivin and XIAP by VEGF in vascular endothelial cells. Biochem Biophys Res Commun 1999; 264: 781-8.

20 Gerber HP, Dixit V, Ferrara N. Vascular endothelial growth factor induces expression of the antiapoptotic proteins $\mathrm{Bcl}-2$ and $\mathrm{A} 1$ in vascular endothelial cells. J Biol Chem 1998; 273: 13313-6.

21 Chen T, Guo L, Zhang L, Shi L, Fang H, Sun Y, et al. Gene expression profiles distinguish the carcinogenic effects of aristolochic acid in target (kidney) and non-target (liver) tissues in rats. BMC Bioinformatics 2006; 7: S20.

22 Sun D, Feng J, Dai C, Sun L, Jin T, Ma J, et al. Role of peritubular capillary loss and hypoxia in progressive tubulointerstitial fibrosis in a rat model of aristolochic acid nephropathy. Am J Nephrol 2006; 26: 363-71.

23 Burgering BM, Coffer PJ. Protein kinase B (C-Akt) in phosphatidylinositol-3-OH kinase signal transduction. Nature 1995; 376: 599602. 